\title{
Increasing complete immunization in rural Uttar Pradesh: Implications for behavior change communication
}

Population Council

Follow this and additional works at: https://knowledgecommons.popcouncil.org/departments_sbsr-rh

Part of the Demography, Population, and Ecology Commons, Family, Life Course, and Society Commons, International Public Health Commons, Maternal and Child Health Commons, and the Public Health Education and Promotion Commons How does access to this work benefit you? Let us know!

\section{Recommended Citation}

Population Council. 2010. "Increasing complete immunization in rural Uttar Pradesh: Implications for behavior change communication," Shaping Demand and Practices to Improve Family Health Outcomes in Northern India Policy Brief no. 8. New Delhi: Population Council. 


\section{Increasing complete immunization in rural Uttar Pradesh: Implications for behavior change communication}

\section{Background}

The Government of India has recommended that a child must be vaccinated against six vaccine-preventable diseases (polio, tuberculosis [TB], diphtheria, whooping cough, tetanus and measles); the recommended schedule for immunization is polio zero and BCG at birth, first dose of DPT and polio at 6 weeks, second dose of DPT and polio at 10 weeks, third dose of DPT and polio at 14 weeks, and measles at 9 months of age $^{1}$. In this study, a child is considered to be fully immunized if he/she receives all doses of the recommended vaccines (irrespective of polio zero given at birth).

Immunization coverage in rural Uttar Pradesh (UP) has remained low despite efforts to strengthen coverage. According to NFHS-3 (2005-06), only 20 percent of children aged 12 23 months (of mothers aged 15-34) were fully immunized in $\mathrm{UP}^{2}$. Full immunization coverage increased to 30 percent in 2007-08 in the corresponding group of children (DLHS-3).

In October 2009, the Population Council conducted a formative study in rural UP to determine the current rate of compliance for recommended schedules of child immunization, identify the barriers and factors facilitating the uptake of full immunization and identify behavior change communication (BCC) initiatives that could accelerate adoption of this practice. The project was funded by the Bill and Melinda Gates Foundation.

\section{Methodology}

The study was conducted in two phases.

First, a survey was conducted covering 4,754 households, 4,472 currently married women aged 15-34 years who had delivered a child in the last three years, 2,274 husbands, 2,372 mothers-in-law, 289 ASHAs, 284 AWWs, 161 ANMs, 316 local private practitioners, 251 panchayat members (including Village Health and Sanitation Committee members) and staff at 144 government health facilities (PHCs and CHCs) from 225 villages in 12 districts spread across the Western, Central and Eastern regions of UP. In the second phase, 308 in-depth interviews were conducted with family-level stakeholders (women, husbands, mothers-in-law), health care providers (ASHAs, AWWs, private practitioners, dais) and panchayat members to complement the information gathered in the quantitative survey. The qualitative study was conducted in 24 villages: eight villages each from three districts, one district from each of the three regions.

\section{Key findings}

Status: The Population Council study shows that in rural UP, among children aged 12-23 months $(\mathrm{N}=1,500), 50$ percent were fully immunized, 34 percent were partially immunized while 16 percent had received no immunization. Notably, there has been a 20

\section{Figure 1: Trend in full immunization and} no immunization, rural UP

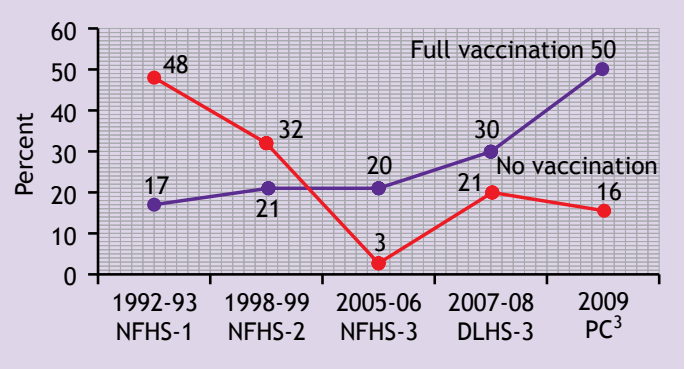

${ }^{1}$ IIPS and Macro International. 2007. National Family Health Survey (NFHS-3): 2005-06: India, Vol. 1. Mumbai: IIPS and Macro International ${ }^{2}$ Data from NFHS-1, NFHS-2, NFHS-3 and DLHS-3 presented in this policy brief are based on an analysis conducted by the Population Council of currently married women aged 15-34 in rural UP who had given birth in three years preceding the survey.

${ }^{3}$ J. Ahmad, M.E. Khan and A. Hazra. 2010. "Increasing Complete Immunization in Rural Uttar Pradesh: Implications for Behavioral Change Communication," in M.E. Khan, Gary Darmstadt, T. Usha Kiran and D. Ganju, eds. Shaping Demand and Practices to Improve Family Health Outcomes: A Formative Study in Rural Uttar Pradesh. New Delhi: Population Council (forthcoming). 


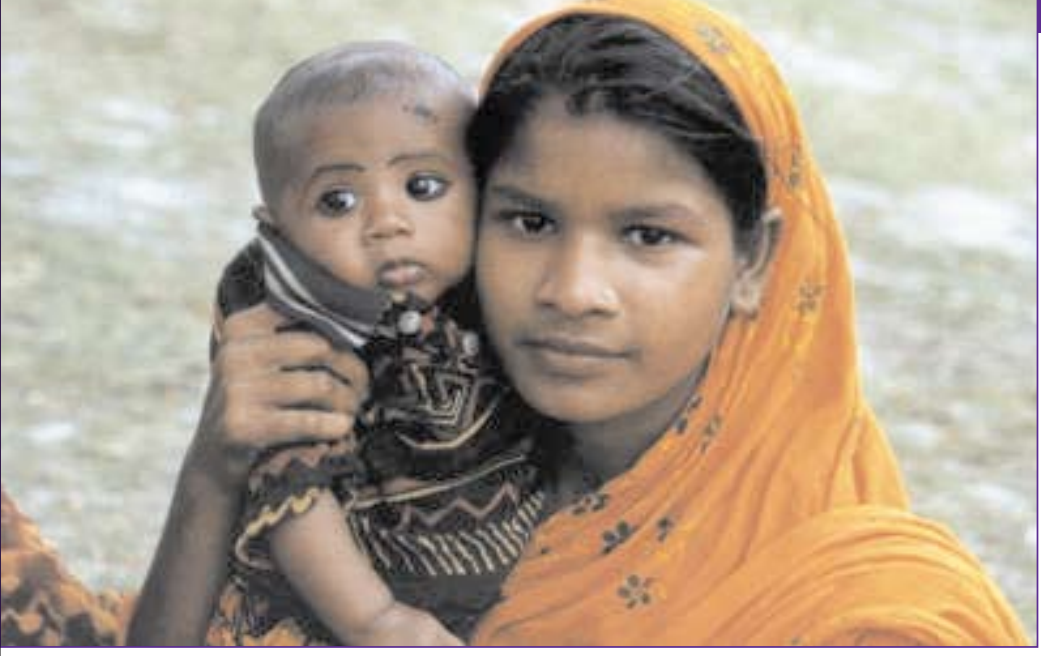

percentage point increase in full immunization from DLHS-3 to the present study (Figure 1). This increase is largely due to the performance-linked fee paid by the state government to ASHAs for facilitating full immunization of childern.

Regional variations are evident in full and partial immunization coverage; just 36 percent of children in the Western region as compared to 57-58 percent in the Central and Eastern regions were fully immunized. This is despite the fact that the Western region is far more developed than the other regions with regard to socio-economic and health infrastructure indicators. A reason for the relatively poor immunization coverage in the Western region is young women's limited mobility.

\section{Barriers}

Low risk perception of disease: At the family level, there is a strong positive association between high perception of risk of a child falling ill or becoming disabled if not fully immunized and adoption of full immunization ( $\mathrm{x}^{2}$ test; $\mathrm{p}<0.001$ ). For example, among women with an eligible child (aged 12-23 months) with low perception of risk (44 percent; $\mathrm{N}=663$ ), just 35 percent had fully vaccinated their child as compared to 62 percent fully immunized children among 835 women with high risk perception. As the number of key

\section{Figure 2: Percentage of children fully immunized by number} of family members perceiving risk if a child is not fully immunized

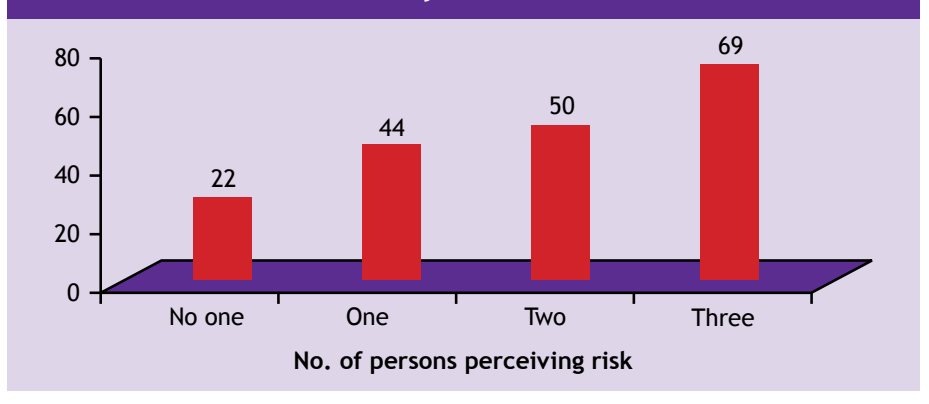

Note: Analysis based on 397 families with an eligible child where the woman, husband and mother-in-law were interviewed.

stakeholders in the family perceiving high risk of acquiring disease if a child is not fully immunized increases, the percentage of fully immunized children in the family also increases (Figure 2).
Lack of faith in vaccination: Lack of faith in vaccination at the family level, particularly among family elders, is a barrier to full immunization. Indeed, lack of faith was a reason reported by 20 percent of women who had not immunized their child $(\mathrm{N}=246)$. The qualitative study corroborates these findings: a mother-in-law commented: "I feel that when we had not given any vaccination to my sons and nothing happened, then nothing will happen to my grandchild also." According to a husband: "Nothing happens due to immunization; whatever God wants will happen."

Lack of vaccine-related knowledge: Apart from polio, knowledge of vaccine-preventable diseases among all women was low: while 73 percent were aware that vaccinations can protect a child against polio, just 35-39 percent were aware that vaccinations can also protect a child against tetanus and measles. Less than 20 percent of women were aware that vaccinations can protect a child against whooping cough, TB and diphtheria. Qualitative research findings also reflect family members' limited knowledge of vaccinations. For example, a woman said: " $I$ don't know how many doses and in which month vaccinations are to be given. I go on my own for vaccination. There nobody tells us when to return for the next dose."

Notably, 37 percent of all women with an eligible child lacked correct knowledge of vaccine-preventable diseases. Yet, among them, approximately 13 percent had fully vaccinated their child. On probing, women revealed that the child had been taken by a relative or neighbor for vaccination or the woman herself had acted on the advice of a frontline health worker to get the child immunized. A key reason for partial immunization is lack of awareness that immunization can be continued even if a child misses a vaccine dose. Among women who had discontinued immunization $(\mathrm{N}=504), 15$ percent had done so because the child had missed a scheduled vaccination day due to various reasons such as the ANM did not turn up to provide vaccination services or the child was ill.

Fear of side effects of vaccination: Among women who had not immunized their child or had partially immunized their child, 38 percent and 13 percent respectively, reported fear of side effects of vaccination as the main reason for not doing so (Table 1). According to a woman, "no vaccination is required; it causes fever, pain and swelling, and the child cries a lot." A few women whose previous child had experienced side effects following vaccination had refused to vaccinate their next child. For example, "I will not give any vaccine to this child; my elder child developed an abscess and got fever after vaccination." Indeed, among women who had fully or partially immunized their child $(\mathrm{N}=1,254)$, 36 percent had not been counseled by providers on the possible side effects of vaccination during their last immunization visit.

Lack of family support: Qualitative study findings show that young mothers' limited mobility and lack of family support were reasons for non-immunization, particularly in the Western region. For example, a woman said: "I want to 
Table 1: Reasons reported by women for no or partial immunization of child (percent)

Reasons

No

Fear of side effects

Lack of knowledge

Lack of faith in immunization

Unaware of place

Unaware of timing/day

Inconvenient timing

ANM absent on scheduled day

Missed one and dropped out

Total

\begin{tabular}{|c|c|c|}
\hline 38 & 13 & 20 \\
35 & 24 & 27 \\
20 & 3 & 8 \\
12 & 4 & 6 \\
10 & 18 & 16 \\
7 & 5 & 5 \\
7 & 13 & 12 \\
1 & 10 & 6 \\
\hline 246 & 504 & 750 \\
\hline
\end{tabular}

Note: Percentages may not add to 100 due to multiple responses.

get my child vaccinated but I don't go out of the house. I also tried to talk to my husband but he doesn't listen to me."

Lack of knowledge of the place and day of immunization: Among women who had not vaccinated their child, 12 percent had not sought immunization services because they were not aware of the place of immunization. Only 57 percent of all women with an eligible child were aware that there is a fixed immunization day when health workers visit their village to provide immunization services. A woman said: "My child has got only one vaccine. Other vaccines have not been given because I don't know the immunization day. I don't know when the ANM comes to the village."

Uncertainty of service provision: Nine percent of women and 11 percent of ASHAs reported non-availability of the ANM on the scheduled immunization day as a reason for no or partial immunization. As a woman noted: "The ANM has not come for the last three months; hence I was not able to get my child vaccinated."

Limited counseling by health workers: Of the women who had been contacted by the ASHA $(\mathrm{N}=1,783)$, only 26 percent reported receiving advice on child immunization. A slightly larger percentage of all husbands and mothers-in-law (35 and 40 percent, respectively) had been similarly advised by the ASHA. The qualitative study corroborates these findings. For example, "My child has not received any vaccination because nobody told me about immunization and when child needs to be given vaccines. One-third of women were not informed by the health provider about the next scheduled immunization day.

\section{Facilitating factors}

Women's education: Among background characteristics, women with a secondary or higher education were three times (OR 3.24, $\mathrm{p}<0.01$ ) more likely than those with no education to fully immunize their child.

Knowledge of the next scheduled immunization day: If women are advised about the next scheduled immunization date, the rate of full immunization increases two and a half times (OR 2.63, p<0.01). Further, women who were aware of the monthly immunization day were about one and half times (OR 1.49, p<0.01) more likely than those who were not aware to fully immunize their child.

Knowledge of the side effects of vaccination: Knowledge of the side effects of vaccination is a strong facilitator for full immunization. Women who were advised by health providers on the possible side effects of vaccination were almost two times (OR 1.75, p<0.01) more likely to fully immunize their child than those who did not receive any advice.

ANC contact is an import focal point for the provision of information on immunization and addressing concerns about the side effects of immunization. The analysis indicates that women who had three or more ANC checkups were more than two times (OR 2.21, p<0.01) more likely to fully immunize their child as compared to those who had no ANC check-up.

Awareness of risk if the child is not fully immunized: Women who perceived high risk of disease, disability or death if the child is not immunized were almost two times (OR 1.81, p<0.01) more likely to fully immunize their child as compared to those who perceived no risk or some risk. The percentage of full immunization increases from 22 percent to 69 percent when the number of stakeholders perceiving risk increases from one to three in a family.

Credibility of frontline health workers as a source of information: 68 percent of women reported trust on the ANM and ASHA as key facilitators for immunization and for information and advice on health issues. Contact and advice from the ASHA on immunization increases the rate of fully immunized children one and half times.

Ensuring the availability of health providers and supplies: Full immunization coverage can be achieved only if BCC efforts are supported by the availability of reliable health services and supplies. If an immunization facility (anganwadi center, sub-center/ PHC) is available within the village or within a radius of $1.5 \mathrm{~km}$, children were two times (OR 2.12, $\mathrm{p}<0.01$ ) more likely to be fully immunized as compared to children in a village where such a facility is not available. Additionally, there is a strong association ( $\mathrm{x}^{2}$ test, $\mathrm{p}<0.01$ ) between full immunization and village population 
size. Most small villages (population $<1,000$ ) and isolated hamlets do not have any such health facility; as a result, 64 percent of children from such villages remain partially immunized or are not immunized.

Implications for the BCC strategy

Audience segmentation: At the macro-level, remote villages with a population of less than 1,000 , without an anganwadi center/ health facility would need special attention. At the family level, the focus should be on economically disadvantaged families and non-literate women. In addition to women, husbands and mothers-in-law should also be the focus of provider counseling.

Media content: A key barrier to immunization uptake is the lack of correct knowledge on immunization at the family level. Multi-media channels should be used to provide information on vaccine-preventable diseases, immunization schedules, village vaccination day, scheduled vaccination days and possible side effects. Besides clients would need to be informed that immunization should not be discontinued if they have missed any dose.

IPC to play a lead role supported by mass media and mid-media channels:

Communication channels should include an appropriate media mix, led by IPC efforts by frontline health workers. As an ASHA suggested, "The way to promote immunization is to go to women's homes and tell families the benefits of immunization." Disseminating information on immunization days in the village using loudspeakers, existing forums like the Village Health and Nutrition Day to reinforce messages and school children to promote awareness in the community on immunization could be effective.
Use of mobile phones: Most ASHAs and ANMs have a mobile phone and an increasing number of families are also accessing this facility. ASHAs should be encouraged to maintain a list of client families that have access to a mobile phone, and use their phones to remind these families about action to be taken (e.g. for child immunization). Providing frontline health workers similar reminders on the phone and ensuring supportive supervision could lead to timely dissemination of messages and necessary action.

Build risk perception at the family level: Given the high correlation between risk perception and immunization uptake, messages need to reach to all key stakeholders in the family (women, mothersin-law, husbands) to inform them of the risks of not immunizing or partially immunizing their child.

Advocacy with state and district officials to strengthen BCC and service provision: Sustained advocacy is also required to address system-level issues if behavior change is to be achieved at the desired pace. The finding that ANMs/ASHAs/AWWs have credibility in the community and are a trusted source of information on health-related issues for families suggests that they can be key agents in behavior change. However, efforts are needed to ensure that aligned messages and comprehensive information on immunization and maternal and child health care are provided through IPC during ANC visits, at the time of discharge from the facility after delivery and during other contacts with the family.

Suggested citation: Population Council. 2010. Increasing complete immunization in Uttar Pradesh: Implications for behavior change communication, Policy Brief No. 8. New Delhi: Population Council.

For additional information, contact: Population Council, Zone 5A, India Habitat Centre, Lodi Road, New Delhi 110003, or email info-india@popcouncil.org

\section{(2) Population Council}

Research that makes a difference

\section{Abt}

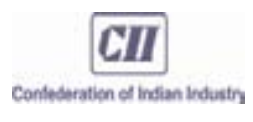

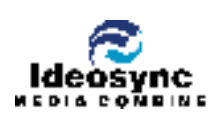

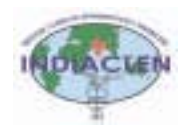

K
s
W
A
M O
Y

The opinions expressed in this publication do not necessarily reflect the views of the funding agencies.

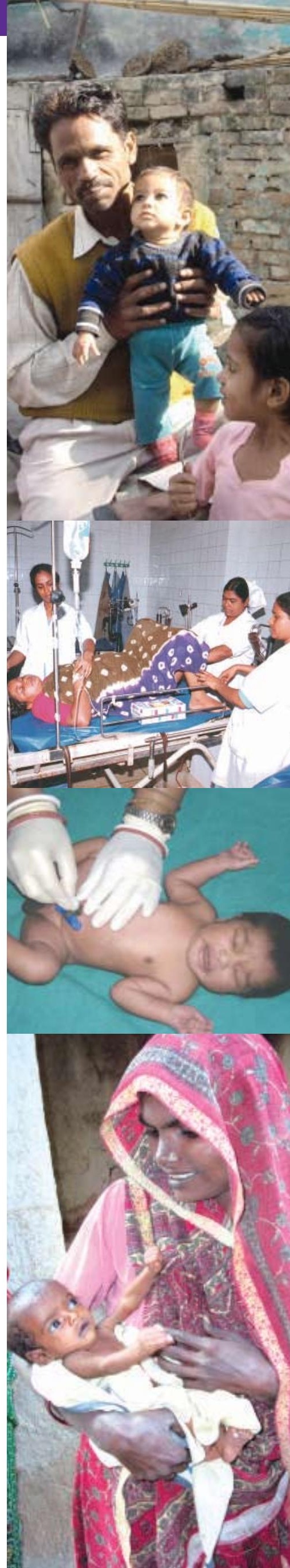

